\title{
Response to Filchner-Ronne Ice Shelf cavity warming in a coupled ocean-ice sheet model - Part 1: The ocean perspective
}

\author{
Ralph Timmermann ${ }^{1}$ and Sebastian Goeller ${ }^{1, a}$ \\ ${ }^{1}$ Alfred-Wegener-Institut Helmholtz-Zentrum für Polar- und Meeresforschung, Bremerhaven, Germany \\ ${ }^{a}$ now at: GFZ German Research Centre for Geosciences, Potsdam, Germany \\ Correspondence to: Ralph Timmermann (ralph.timmermann@awi.de)
}

Received: 12 May 2017 - Discussion started: 19 May 2017

Revised: 18 August 2017 - Accepted: 21 August 2017 - Published: 21 September 2017

\begin{abstract}
The Regional Antarctic ice and Global Ocean (RAnGO) model has been developed to study the interaction between the world ocean and the Antarctic ice sheet. The coupled model is based on a global implementation of the Finite Element Sea-ice Ocean Model (FESOM) with a mesh refinement in the Southern Ocean, particularly in its marginal seas and in the sub-ice-shelf cavities. The cryosphere is represented by a regional setup of the ice flow model RIMBAY comprising the Filchner-Ronne Ice Shelf and the grounded ice in its catchment area up to the ice divides. At the base of the RIMBAY ice shelf, melt rates from FESOM's ice-shelf component are supplied. RIMBAY returns ice thickness and the position of the grounding line. The ocean model uses a pre-computed mesh to allow for an easy adjustment of the model domain to a varying cavity geometry.

RAnGO simulations with a 20th-century climate forcing yield realistic basal melt rates and a quasi-stable grounding line position close to the presently observed state. In a centennial-scale warm-water-inflow scenario, the model suggests a substantial thinning of the ice shelf and a local retreat of the grounding line. The potentially negative feedback from ice-shelf thinning through a rising in situ freezing temperature is more than outweighed by the increasing water column thickness in the deepest parts of the cavity. Compared to a control simulation with fixed ice-shelf geometry, the coupled model thus yields a slightly stronger increase in ice-shelf basal melt rates.
\end{abstract}

\section{Introduction}

The mass flux from the Antarctic ice sheet to the Southern Ocean is dominated by iceberg calving and ice-shelf basal melting. Until recently, it was assumed that iceberg calving was the dominant sink of Antarctic ice sheet mass, but ice-shelf basal melting is now estimated to outweigh all other processes (Depoorter et al., 2013; Rignot et al., 2013). Ice shelves have been shown to buttress the flow of outlet glaciers and ice streams (e.g. De Angelis and Skvarca, 2003; Dupont and Alley, 2005). Changes in ice-shelf thickness and grounding line location may therefore alter the discharge of ice grounded above floatation, and thus contribute to global sea level rise. The acceleration of mass loss from the Antarctic ice sheet since the 1990s (Rignot et al., 2011) has been attributed to enhanced ice-shelf basal melting and related ice-shelf thinning particularly in the Amundsen and Bellingshausen seas (Pritchard et al., 2012).

Models of ice-shelf-ocean interaction are not only used in hindcasts or sensitivity studies, but also in attempts to project future melt rates, either with idealized changes in forcing (e.g. Kusahara and Hasumi, 2013) or with atmospheric forcing derived from coupled climate model projections. Using atmospheric output from the HadCM3 climate model, Hellmer et al. (2012) found the potential of a rapid warming of the southwestern Weddell Sea continental-shelf waters by a redirected coastal current. In the Jacobs et al. (1992) terminology, the replacement of cold shelf water by water originating from Warm Deep Water (WDW) leads to a shift from Mode 1 to Mode 2 melting, and thus to dramatically increased melt rates for the Filchner-Ronne Ice Shelf (FRIS). Timmermann and Hellmer (2013) showed that the surface 


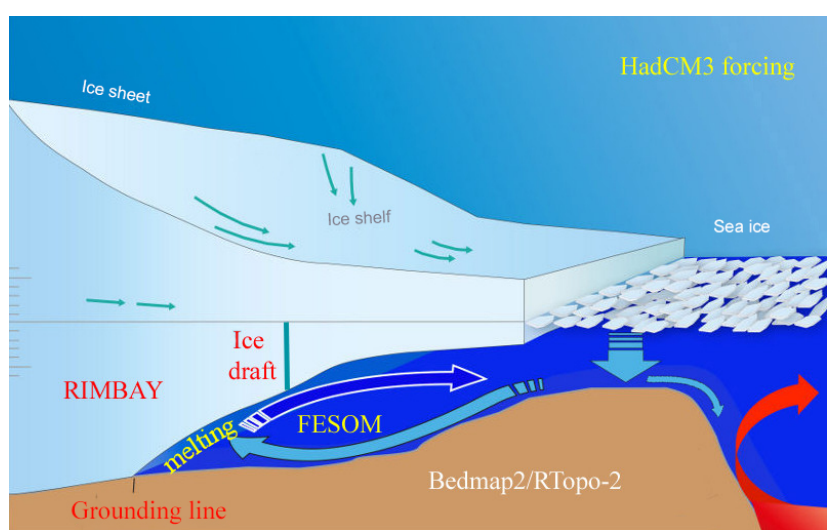

Figure 1. Schematic representation of the Filchner-Ronne Ice Shelf cavity, including cavity/shelf water circulation for the present-day Mode 1 melting/cold-water ice-shelf scenario.

freshwater flux on the Weddell Sea continental shelf, which is governed by sea ice formation, and thus largely determined by atmospheric forcing, is critical in allowing or preventing this transition in the melting mode. Observational evidence of warm pulses already arriving at the ice-shelf front (Darelius et al., 2016) indicates that this is a realistic scenario.

All model studies mentioned above assumed a static iceshelf geometry even with simulated melt rates near the grounding line rising to almost $20 \mathrm{~m} \mathrm{year}^{-1}$ (Timmermann and Hellmer, 2013). To overcome this deficiency and study ice-shelf-ocean interaction in a warming climate in a consistent way, we coupled the Finite Element Sea-ice Ocean Model (FESOM) to a regional setup of the ice flow model RIMBAY (Thoma et al., 2014) and forced the coupled model with output from HadCM3 that has been obtained for present-day climate and the A1B scenario (Collins et al., 2011). This paper describes the coupling procedure and reports on the solutions we found for a suite of technical challenges (Sect. 2). A 250-year-long coupled model run with climate-projection forcing serves as the reference simulation and is compared to control experiments with (i) continuous present-day forcing and (ii) static ice-shelf geometry (Sect. 3). The focus of the analysis here is on processes and sensitivities in the sub-ice-shelf cavity. Ice dynamics and ice sheet mass balance will be discussed in the companion paper (Part 2: The ice perspective; Goeller and Timmermann, 2017).

\section{Regional Antarctic ice and Global Ocean model (RAnGO)}

\subsection{Overview}

RAnGO combines a regional model of the Antarctic ice sheet with a global ocean model. The coupled system consists of a global configuration of FESOM (Timmermann et al.,

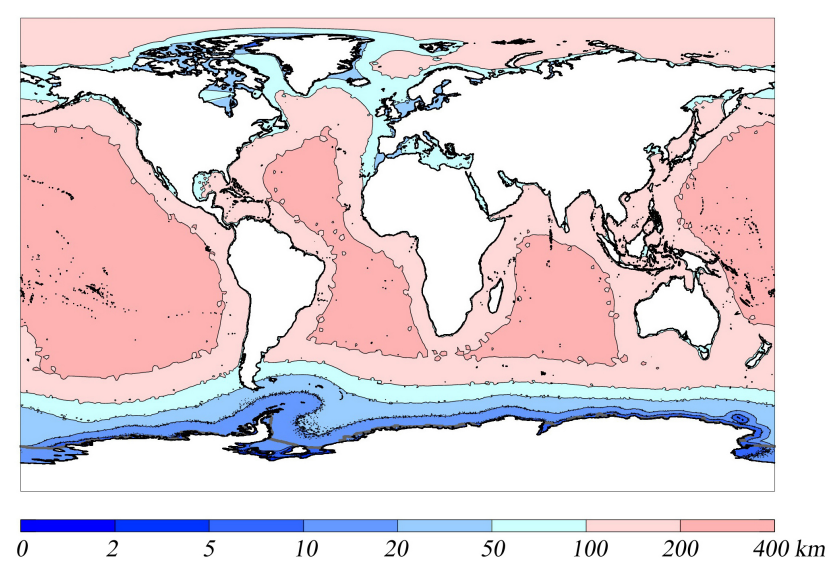

Figure 2. Horizontal resolution of RAnGO's ocean component. Note the nonlinear colour scale.

2012), and a regional setup of the Revised Ice Model Based on frAnk pattYn (RIMBAY; Thoma et al., 2014). While the FESOM domain covers the world ocean including the subice-shelf cavities in the Southern Ocean, the RIMBAY setup comprises the FRIS and the relevant catchment basin up to the ice divides. The interface between the two models is the FRIS base (Fig. 1). All other ice shelves are modelled with fixed geometry. As for the stand-alone model runs of Hellmer et al. (2012), the coupled model is forced by atmospheric output from the HadCM3 climate model.

\subsection{The ocean component: FESOM}

FESOM is a primitive-equation hydrostatic ocean model that is solved on a horizontally unstructured mesh (Wang et al., 2014). It comprises a dynamic-thermodynamic sea ice model (Danilov et al., 2015). The ice-shelf component (Timmermann et al., 2012) goes back to the Hellmer and Olbers (1989) three-equation model of ice-shelf-ocean interaction with a velocity-dependent parameterization of boundary layer heat and salt fluxes according to Holland and Jenkins (1999).

The model is run on a global mesh with a horizontal resolution varying from $1 \mathrm{~km}$ along the FRIS grounding line to $340 \mathrm{~km}$ in the deep Atlantic and Pacific basins (Fig. 2). It uses a hybrid vertical coordinate with 22 sigma levels south of the $2500 \mathrm{~m}$ isobath surrounding the Antarctic continent and up to $36 z$ levels outside this domain. Antarctic sub-ice-shelf cavities are thus all inside the sigma domain, which allows for a smooth representation of the ice-shelf base. The ice-shelf front is approximated by a ramp-like shape; with a horizontal resolution between 10 and $16 \mathrm{~km}$ in this area, the deviation from the true geometry is mostly confined to $50(100) \mathrm{km}$ inwards of the Filchner (Ronne) ice-shelf front. We apply a minimum water column thickness of $50 \mathrm{~m}$ for all sub-ice cavities. 


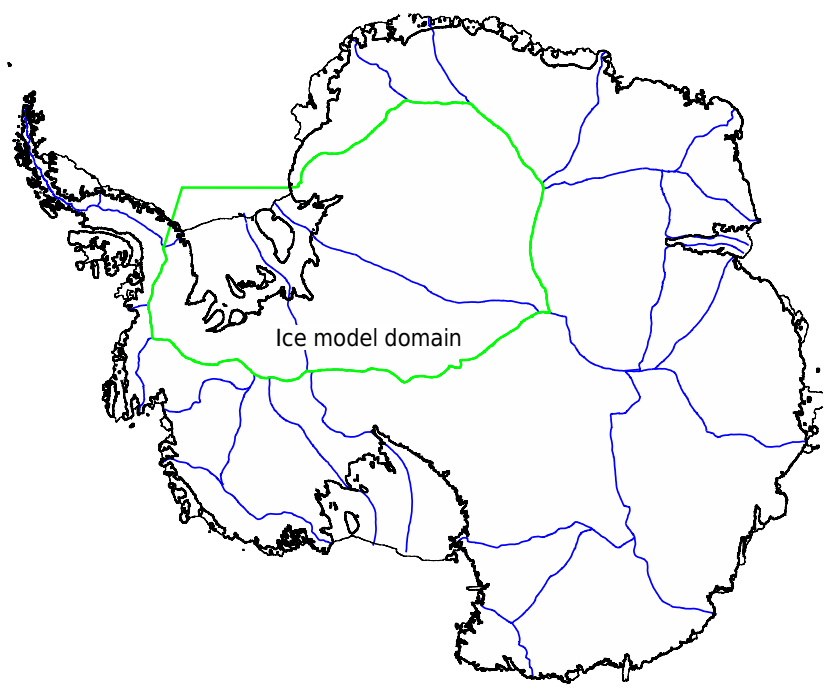

Figure 3. Antarctic ice sheet with coast and grounding lines (black) and the ice divides (green and blue) from Antarctica's Gamburtsev Province Project (AGAP). The green lines indicate the RIMBAY model domain in this study.

An early version of RTopo-2 (Schaffer et al., 2016) has been used to derive ocean bathymetry and the ice-shelf draft and grounding lines for all cavities with fixed geometry. With the present-day ice-shelf configuration for FRIS, the FESOM mesh comprises a total of $\approx 2.6 \times 10^{6}$ nodes, $1.1 \times 10^{5}$ of which are surface nodes (where the term surface equally refers to open ocean and ice-shelf base). The model is run with a default time step of $90 \mathrm{~s}$ owing to the very fine horizontal resolution along the FRIS grounding line and a minimum sigma layer thickness of just over $2 \mathrm{~m}$. For several situations with eddies running into shallow sections of the FRIS cavity, it turned out to be necessary to decrease the ocean model time step to $4 \mathrm{~s}$.

\subsection{The ice component: RIMBAY}

RIMBAY (Thoma et al., 2014) is a three-dimensional thermomechanical multi-approximation ice-shelf/sheet model going back to the ice flow model of Pattyn (2003). Within the RAnGO experiments, the ice model domain comprises the FRIS and its upstream catchment area of grounded ice, confined by the surrounding ice divides (Fig. 3). Ice velocities are calculated following the hybrid approach which combines the shallow-ice and the shallow-shelf approximations. A basal friction correction at the grounding line after Feldmann et al. (2014) ensures a smooth transition between grounded and floating ice and thus a realistic grounding line migration.

The ice model is run at a horizontal resolution of $10 \mathrm{~km}$ with 41 terrain-following sigma layers and a time step of 0.1 years. Bedmap2 (Fretwell et al., 2013) data are used for bedrock topography and initial ice thickness. Since Bedmap2
Launch procedure and coupling

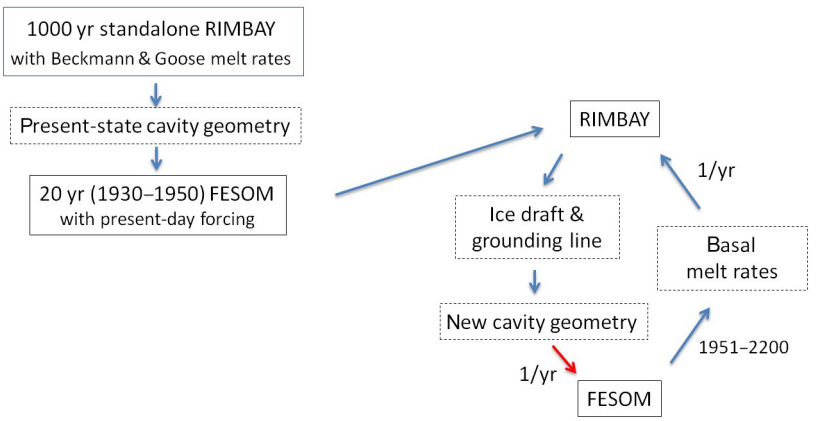

Figure 4. RAnGO initialization and coupling scheme. The red arrow indicates the most time-consuming element of the model coupling.

is also the source for the Antarctic ice and bedrock relief in RTopo-2, all topographies are fully consistent within RAnGO.

\subsection{Model spinup and coupling}

First, we perform a 1000-year stand-alone RIMBAY simulation. This ice model spinup is forced by present-day surface temperatures (Comiso, 2000), accumulation rates (Arthern et al., 2006) and geothermal heat flux (Shapiro and Ritzwoller, 2004). Basal melt rates are parameterized according to Beckmann and Goose (2003). As a result, ice dynamics are in a quasi-stationary steady state and ice thickness, ice velocity, and grounding line position match current observations very well. Additional figures and a thorough discussion of the ice model spinup are presented in our companion paper (Part II: the ice perspective; Goeller and Timmermann, 2017).

With this RIMBAY present-day cavity geometry, we integrate FESOM for 21 years (1930-1950) using atmospheric forcing from the 20th-century simulation of the HadCM3 climate model. Annual mean basal melt rates for FRIS from the last year (1950) are then transferred back to RIMBAY, which starts the RAnGO coupled model loop (Fig. 4).

For each of the cycles within the coupled RAnGO system, FRIS basal melt rates averaged over year $N$ are obtained from FESOM and passed to RIMBAY, which is then stepped forward for that same year $N$. From the simulated ice draft and grounding line location at the end of RIMBAY year $N$, a new cavity geometry is derived and an updated FESOM mesh is generated. FESOM's prognostic variables are projected onto the new mesh (details below), and FESOM is then integrated over year $N+1$. Basal melt rates are averaged over FESOM year $N+1$ and passed to RIMBAY, and the cycle repeats itself with RIMBAY running year $N+1$.

A 1-year coupling time step is long compared to the relevant timescales in the ocean but short compared to the typical timescales for ice dynamics or the ice mass budget. The fact that variations of RIMBAY ice thickness distribution, 


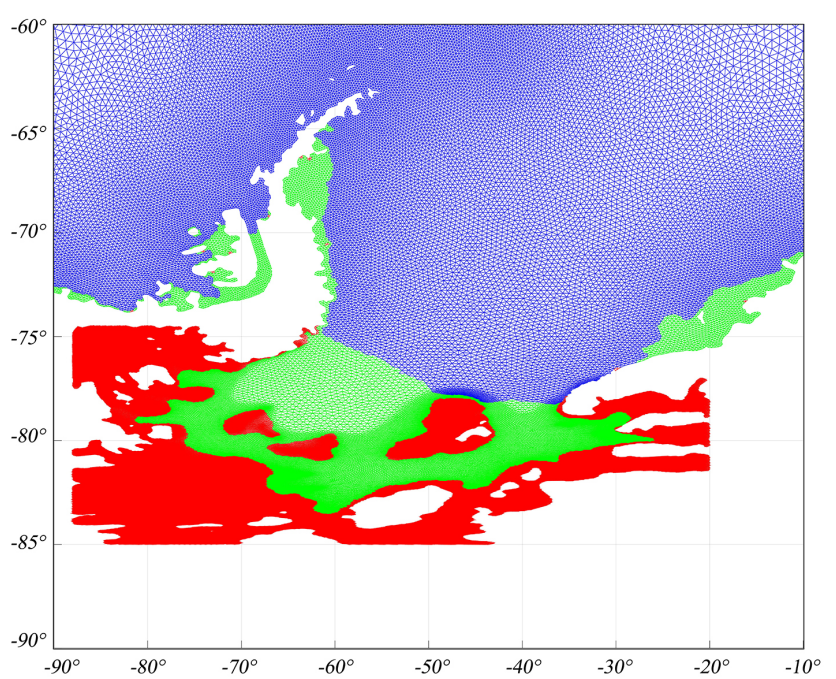

Figure 5. Precomputed and actual FESOM mesh in the Weddell Sea/FRIS sector: blue triangles indicate open ocean; green triangles indicate ice-shelf cavities in the RAnGO geometry for simulated year 2000 (i.e. at the end of the 20th-century spinup). Red triangles refer to elements that have been created in the initial mesh but are removed for the year 2000 geometry because they were found to be covered with grounded ice (potential ocean mesh in a warming scenario).

grounding line location, and melt rate patterns are small for each coupling time step indicates that this coupling strategy is adequate.

\subsection{Dynamic FESOM mesh modification}

Adjustment of the model domain to a varying ice-shelf geometry is a natural part of RIMBAY and is rather straightforward to implement for a finite-difference ocean model with a land-sea mask. For FESOM, the computational mesh only exists in the ocean and has to satisfy certain criteria in order to ensure numeric stability and efficiency. For stand-alone FESOM applications (e.g. Timmermann et al., 2012) we use an iterative method to generate surface meshes in which the size of triangles smoothly varies according to the desired resolution, while at the same time triangles approximate the ideal of being equilateral as well as possible. For a mesh with about $10^{5}$ surface nodes, the algorithm takes about 2 days to converge - which clearly prevents it from being used as part of a coupling interface.

To reduce the mesh generation overhead, we generated an initial surface grid that covers the full RTopo-2 ocean (blue and green triangles in Fig. 5) plus all ice around FRIS that is grounded on bedrock deeper than $100 \mathrm{~m}$ below sea level (red triangles in Fig. 5). This criterion to define the "potentially ungrounding" area adjacent to the currently floating ice shelf proves to be well on the safe side for any grounding line movement in our coupled model runs. Mesh resolution along the present-day grounding line and in the po- tentially ungrounding area is about $1 \mathrm{~km}$ to describe grounding line migration as smoothly as possible. For each topography/cavity geometry to be run with RAnGO, the coupler removes all grid nodes that are covered by grounded ice. The remaining ocean grid nodes are renumbered consecutively. The full three-dimensional grid is then created from this new surface mesh, with the terrain-following vertical coordinate easily adjusting to any change in water column thickness due to a varying ice-shelf draft.

During this procedure, the vast majority of finite element mesh nodes keep their position (despite being renumbered), so that no horizontal interpolation is necessary for the ocean state variables outside the immediate vicinity of the grounding line. This makes it much easier to ensure the conservation of heat and salt. Wherever new ocean (i.e. cavity) nodes are created, ocean temperature, salinity, and sea surface height are taken from the nearest existing neighbour grid node. Again, the small variations per coupling step make this simple "no-flux" approach justified.

\subsection{Computational load}

Coupling has been implemented in an "offline" way with RIMBAY and the RAnGO coupler running on local servers and FESOM relying on a massively parallel supercomputing system. Given that (1) model output is in any case transferred to local disks for postprocessing and analysis and that (2) the updated mesh configuration files are comparatively small, the overhead arising from the file transfer necessary in our offline approach is negligible.

To run a typical model year with the current configuration of RAnGO requires about $7 \mathrm{~h}$ on 528 CPUs for FESOM, less than $10 \mathrm{~min}$ for RIMBAY, and almost $2.5 \mathrm{~h}$ for the coupling procedures. Within the coupler, more than $90 \%$ of the time is spent on the construction of the three-dimensional, tetrahedral mesh from the updated surface grid. A more efficient algorithm that starts from the existing three-dimensional mesh and only applies corrections where necessary is currently being developed.

\subsection{Experiments}

As stated in Sect. 2.4, 1951 is the first year of the coupled RAnGO simulation. We integrated the coupled model until 1999 using atmospheric output ( $10 \mathrm{~m}$ wind speed, $1.5 \mathrm{~m}$ air temperature, $1.5 \mathrm{~m}$ specific humidity, surface moisture flux, downward long- and shortwave radiation, total precipitation) from the HadCM3 20th-century simulation. This experiment is referred to as the RAnGO 20C simulation. HadCM3 data for the A1B scenario have been used to conduct the $R A n G O$ $A 1 B$ simulation for the period 2000-2199. The suite of the RAnGO 20C (1950-1999) + AlB (2000-2199) model runs serves as the reference simulation for analysis in this paper. A control run with present-day climate (RAnGO CTRL) 


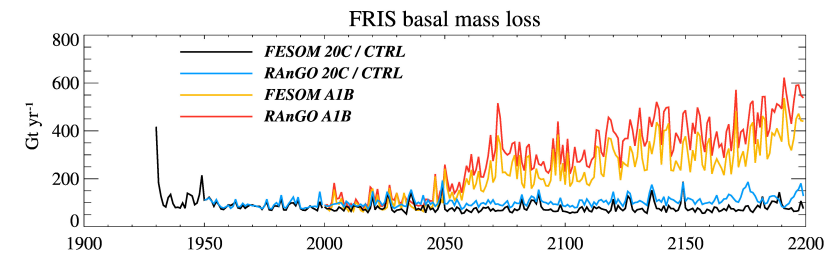

tween the two experiments is much smaller than the (modelled) interannual variability.

Maximum melt rates for present-day climate (Fig. 7a) are about $5 \mathrm{~m}_{\text {year }}{ }^{-1}$ and occur in the deepest parts of the cavity close to the grounding lines of Support Force Glacier and Foundation Ice Stream, where the ice base reaches 1100 and $1400 \mathrm{~m}$ below sea level, respectively (Fig. 7d), and the in situ freezing point is about $1 \mathrm{~K}$ below the surface freezing point. Melt rates between 3 and $5 \mathrm{~m}_{\text {year }}{ }^{-1}$ are suggested for Evans and Rutford Ice streams in the western sector of Ronne Ice Shelf, which is consistent with estimates based on ice flux divergence (Joughin and Padman, 2003).

An extended area of marine ice formation is suggested north of (i.e. downstream from) the Henry and Korff Ice rises. While this pattern is consistent with the observed locations of marine ice (Lambrecht et al., 2007), accretion rates in most of the refreezing area are smaller than in the estimates of Joughin and Padman (2003).

Two additional hot spots of marine ice formation (at rates exceeding $1.0 \mathrm{~m} \mathrm{year}^{-1}$ ) are associated with the outflow of Ice Shelf Water (ISW) in the Filchner and Ronne troughs. For Filchner Trough, this is again consistent with Joughin and Padman (2003), although their data and the marine ice thicknesses observed by Lambrecht et al. (2007) suggest a more pronounced freezing pattern on the western side. For the western side of Ronne Trough, marine ice formation along the coast is consistent with the sub-ice circulation, as suggested by Nicholls et al. (2004).

Modelled present-day cavity geometry agrees well with has been performed twice repeating the HadCM3 1900-1999 forcing.

Next to the coupled RAnGO simulation launched from the end of 1950, an uncoupled FESOM experiment with the RIMBAY present-day cavity geometry prescribed has been conducted. Like its RAnGO counterpart, this experiment starts with a FESOM $20 \mathrm{C}$ simulation and splits into a $F E$ $S O M A I B$ and a FESOM CTRL branch at the beginning of the 21 st century.

\section{Results}

\subsection{Ice-shelf basal melt rates and hydrography}

\subsubsection{Present-day climate in FESOM and RAnGO}

Time series of simulated mean basal melt rates in the FESOM $20 C$ and $R A n G O 20 C$ simulations (black and blue lines in Fig. 6) indicate that ice-shelf-ocean interaction approaches a quasi-steady state within less than a decade after the initialization with a relatively warm water mass in the FRIS cavity. Mean basal mass loss over the period 1950-1999 amounts to $87 \mathrm{Gt} \mathrm{year}^{-1}$ in the fixed-geometry FESOM experiment and to $93 \mathrm{Gt} \mathrm{year}^{-1}$ in the fully coupled RAnGO model run. Both are well within the range of observational estimates (e.g. $50 \pm 40 \mathrm{Gt} \mathrm{year}^{-1}$, Depoorter et al., 2013, vs. $155 \pm 35$ Gt year $^{-1}$, Rignot et al., 2013); the difference bethe location of grounding lines in Bedmap2, except for the three narrow ice streams feeding the western sector of Ronne Ice Shelf. Due to small ice thickness and bedrock gradients, the grounding line positions in this area are highly sensitive to ice thickness changes during the RIMBAY spinup. A stringent validation of modelled FRIS topography is provided in Part II of this paper.

\subsubsection{FESOM and RAnGO A1B projections}

Most notably after 2050, the two experiments start to deviate from each other according to the scenario chosen (see Fig. 6). The A1B simulation with RAnGO (and also with fixed-geometry FESOM) features a rapid rise of FRIS basal melt rates during the second half of the 21st century, followed by a more gradual increase during the 22nd century. By the 2190s, basal mass loss for FRIS has increased to about $540 \mathrm{Gt}_{\text {year }}{ }^{-1}$ in the RAnGO AlB simulation, which corresponds to a factor of 6 increase compared to the 20th-century situation. Melt rates along the grounding line in this situation (Fig. 7b) exceed $12 \mathrm{~m}$ year $^{-1}$; areas of refreezing have vanished almost completely. In contrast to the 1990s case, there now is a strong signature of Jacobs et al. (1992) "Mode 3" melting with melt rates up to $20 \mathrm{~m}_{\text {year }}{ }^{-1}$ along the Filchner ice front. 
Basal melt rates
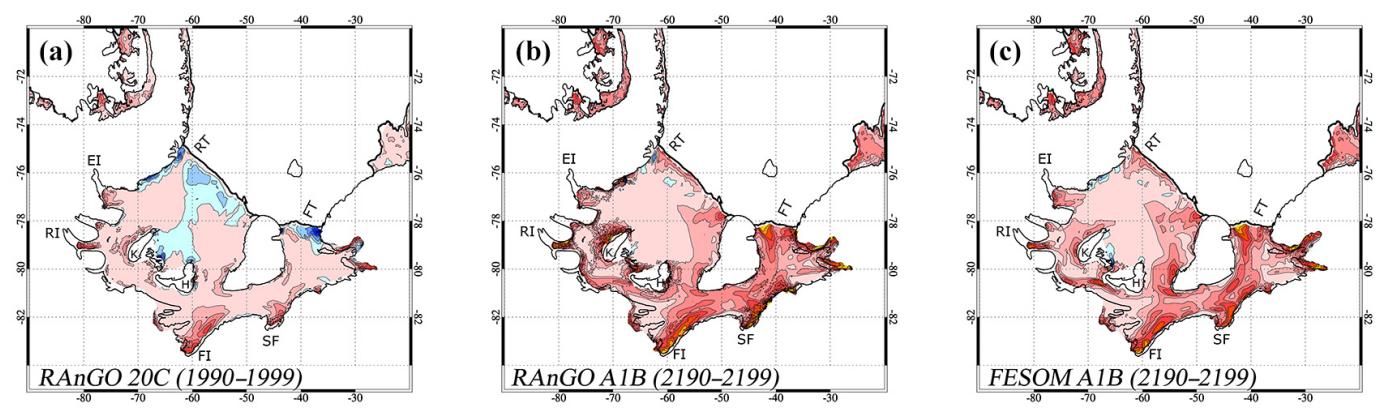

$\begin{array}{llllllllllllllllll}-2.0 & -1.5 & -1.0 & -0.7 & -0.4 & -0.2 & 0.0 & 0.5 & 1.0 & 2.0 & 3.0 & 5.0 & 8.0 & 12.0 & 17.0 & 22.0 & \mathrm{~m} / \mathrm{yr}\end{array}$

Ice shelf draft
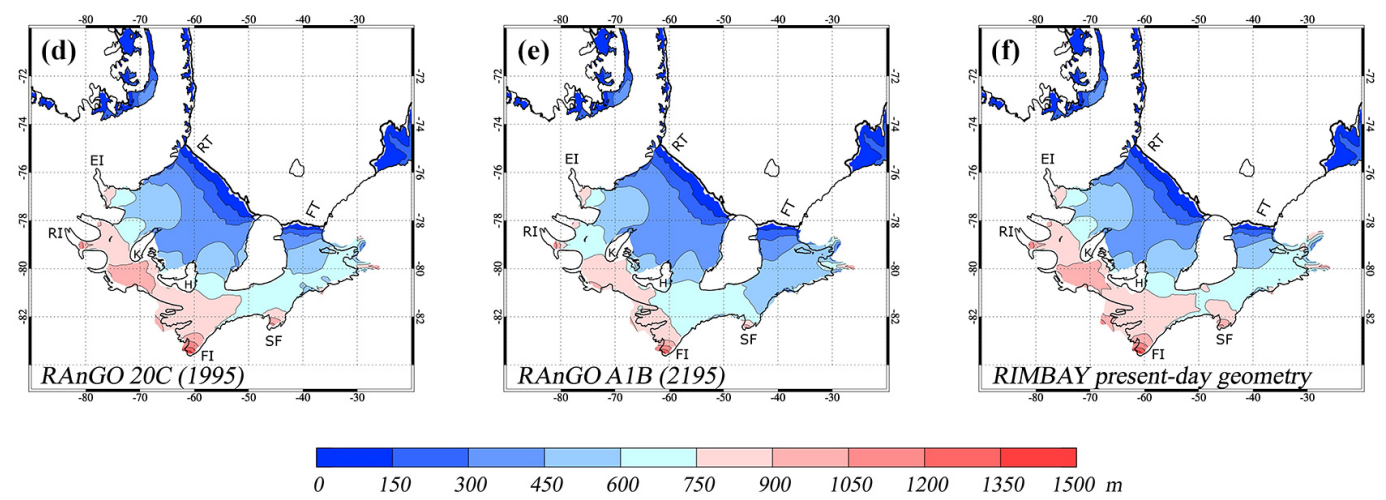

Figure 7. Ten-year mean basal melt rates in the RAnGO 20C experiment for 1990-1999 (a), in RAnGO A1B for 2190-2199 (b), and in FESOM A1B for 2190-2199 (c). Corresponding ice-shelf drafts from the RAnGO 20C/A1B simulation for 1995 (d) and 2195 (e), and in the RIMBAY present-day geometry (f). Abbreviations indicate the locations of Support Force Glacier (SF), Foundation Ice Stream (FI), Evans Ice Stream (EI), Rutford Ice Stream (RI), Henry Ice Rise (H), Korff Ice Rise (K), Ronne Trough (RT), and Filchner Trough (FT). Coloured areas represent modelled cavity geometries. Black lines denote coast and grounding lines from RTopo-2.

The strongest increase in basal melt rates occurs between 2050 and 2070. Like in the experiments of Hellmer et al. (2012) and Timmermann and Hellmer (2013), this is caused by a flow of Modified Warm Deep Water (MWDW) onto the continental shelf and into the sub-ice-shelf cavity (Fig. 8). In contrast to the former FESOM experiments, which adopted a water column thickness of about $200 \mathrm{~m}$ southwest of Henry Ice Rise from RTopo-1 (Timmermann et al., 2010), slightly thicker ice in RIMBAY and a better representation of bottom topography in the RAnGO (FESOM) simulations discussed here lead to a water column thickness of only $120 \mathrm{~m}(90 \mathrm{~m})$ in the channel, and thus prevent a rapid spreading of warm water into the Ronne cavity.

The change in hydrography in the second half of the 21 st century is very similar between the coupled RAnGO simulation and the uncoupled FESOM experiment with fixed cavity geometry (not shown). Area-mean basal melt rates in $F E$ $S O M A I B$ follow the $R A n G O A 1 B$ evolution very closely until about 2050 (top panel in Fig. 6). Differences increase within a few decades after the onset of cavity warming, with the fixed-geometry melt rates always staying below their RAnGO counterparts. With $418 \mathrm{Gt} \mathrm{year}^{-1}$ for FESOM AlB, the mean basal mass loss over the period 2190-2199 is about $20 \%$ lower than in the coupled RAnGO simulation. The distribution of melt rates, however, is very similar between RAnGO AlB and FESOM AlB (Fig. 7b, c).

Throughout the integration, the interannual (year-to-year) variability of area-mean melt rates is very similar between the coupled and the uncoupled model runs. Summerintensified "Mode 3" melting along the ice front is the dominant mechanism here; its year-to-year fluctuations are governed by variations of summer sea ice extent and summer ocean surface heating. The magnitude of these anomalies and the relative importance of "Mode 3" melting increase during the 21 st and 22nd centuries as a response to a decreasing sea ice cover in the southern Weddell Sea: with increasing areas of open water, sea surface temperature can diverge from the surface freezing point temperature more easily, so that interannual variability leaves a stronger footprint on the properties 
(a)

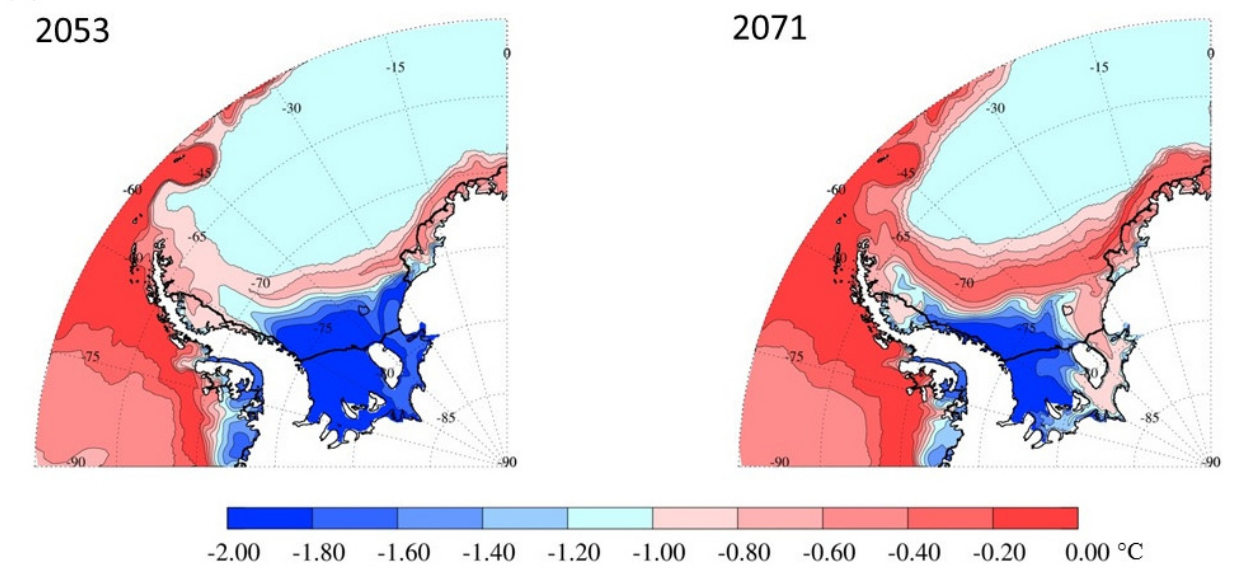

(b)

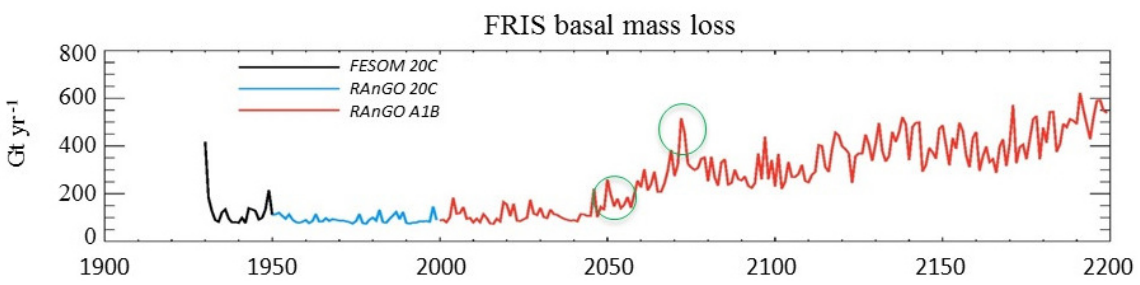

Figure 8. (a) Simulated bottom temperature for 2053 and 2071 in the $R A n G O A 1 B$ experiment. Panel (b) indicates the corresponding points in time on the time series of annual-mean basal mass loss.

of water getting in touch with the ice-shelf base along the ice front.

\subsubsection{FESOM and RAnGO 20C control experiments}

In contrast to the regime shift suggested by the $A 1 B$ experiments, the control runs with a perpetual 20th-century forcing (black and blue lines in Fig. 6) preserve the "cold-water ice shelf" state of the original FESOM $20 \mathrm{C}$ and RAnGO 20C simulations with only little change in the distribution and area-average of basal melt rates. The rapid cavity warming caused by an inflow of MWDW does not occur in these simulations.

\subsection{Ice-shelf thickness, area, and mass}

\subsubsection{RAnGO A1B experiments}

Owing to the increasing basal melt rates in the A1B scenario, FRIS in the RAnGO AlB simulation continuously loses mass from 2050 onwards (Fig. 6, middle panel). Between the 1990 s and the 2190s, FRIS mass decreases by $1.4 \times 10^{4} \mathrm{Gt}$ (i.e. $6.1 \%$ ). Consistent with the location of the highest melt rates, the strongest thickness decrease occurs at the inflow of Support Force Glacier (Fig. 9). At the maximum, ice-shelf draft (thickness) is reduced by 225 (286) $\mathrm{m}$ between 1995 and 2195 here. This is also one of the few locations with a substantial grounding line retreat (green areas in Fig. 9). Despite the fact that melt rates (and the melt rate increase) are of similar magnitude at the floating parts of Foundation Ice Stream, ice draft reduction does not exceed $150 \mathrm{~m}$ and the grounding line remains stable there. This discrepancy will be analysed in Part II of this paper.

Other locations of substantial grounding line retreat are at the Möllereisstrom, the Institute Ice Stream, and at the Henry and Korff Ice rises; the Doake Ice Rumples become detached from the ice-shelf base. The area of floating ice (Fig. 6, lower panel) increases by $1.15 \times 10^{10} \mathrm{~m}^{2}$ (i.e. $2.8 \%$ ).

While ice-shelf thickness trends are small for the northern sector of Ronne Ice Shelf, a substantial thinning is also found at the Filchner Ice Shelf front. This is associated with the increasing rate of "Mode 3" melting during the increasingly long summer season (Fig. 7c), and thus reflects the impact of a decreasing sea ice coverage/increasing summer sea surface temperature on basal melting near the ice-shelf front.

\subsubsection{Present-day climate control experiment}

In the RAnGO control run with perpetual 20th-century forcing, FRIS mass at the end of the 22nd century differs from the 1990s state by less than $1 \%$ (blue line in Fig. 6, middle panel). In the first half of the 21 st century, a positive trend in the floating ice area is very similar between the control run and the A1B experiment (blue and red lines in Fig. 6, bottom panel), which indicates that the grounding line location for simulated FRIS in RAnGO is not in a strict steady state even for perpetual 20th-century forcing. Given the indications for 


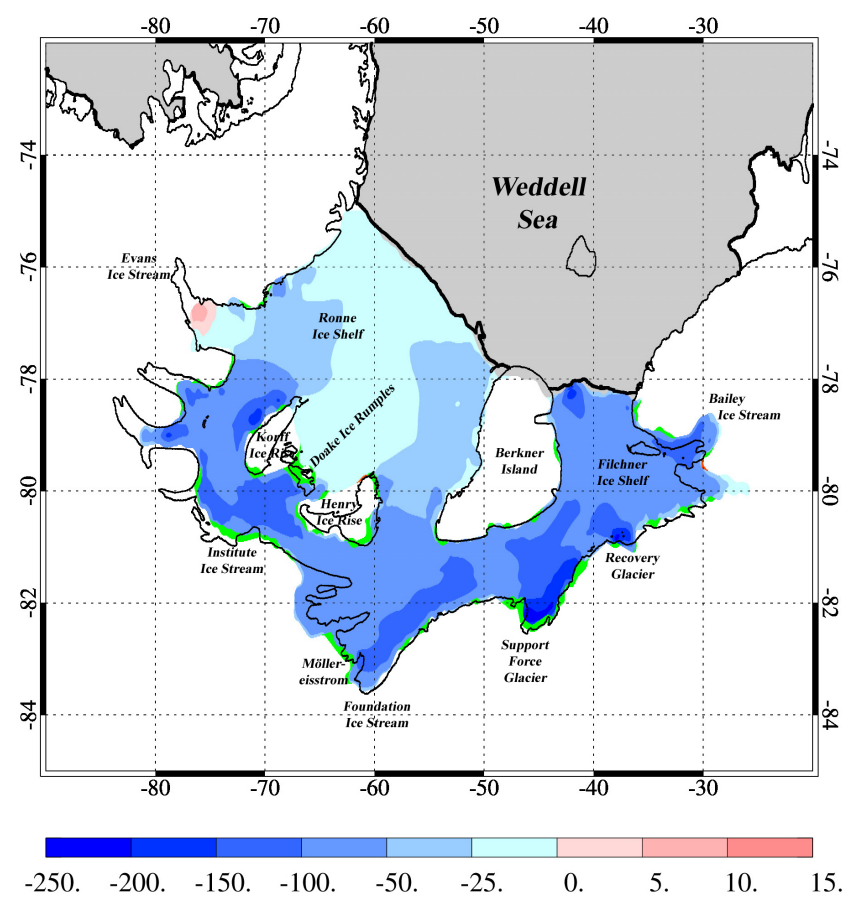

Figure 9. Simulated ice draft change (m) for FRIS from 1995 to 2195 in the RAnGO 20C/A1B experiment. Note the nonlinear colour scale. Green colour indicates areas of originally grounded ice that becomes afloat. Two small red patches represent areas of floating ice that becomes grounded. Thin (thick) black lines indicate coast/grounding lines (ice-shelf fronts) from RTopo-2.

a gradual FRIS thickness loss during the first decade of the 21st century (Paolo et al., 2015) this might well be consistent with the true current situation. In any case, this model background variability is very small compared to the divergence between the two simulations after $\approx 2070$.

\subsection{Thickness-melt-rate feedback}

As has been discussed in Sect. 3.1.2, simulated basal melt rates increase by roughly a factor of 6 between the 1990s and the 2190s in the RAnGO AIB and FESOM AIB simulations. Taking a more quantitative view, we find an increase factor of 6.1 for $R A n G O A 1 B$ vs. only 5.4 for FESOM AlB. We also note that the area-mean melt rate in $R A n G O A 1 B$ is always higher than in FESOM AlB (Fig. 6). Given that a reducing ice draft implies a rising in situ freezing temperature and thus a reducing melt potential for any warm water mass flowing into the cavity, this is not necessarily an obvious result - instead it would have appeared plausible to assume that a reducing ice thickness would reduce (not increase) the basal melt rate in a warming scenario like the one discussed in this study. In this section, we will therefore look into the processes that lead to an increased melt for a thinning ice shelf.

From the RAnGO and FESOM melt rate maps for the 2190s (Fig. 7b, c) a systematic change introduced by the tran- sition from a fixed geometry to a coupled model is not obvious. A map of the difference between the two fields (Fig. 10, panel a) reveals that in many places with a retreating grounding line, an increased melt in newly ungrounded areas is at least partly compensated by reduced melt in areas along the old grounding line location. Even in this warm-water-inflow scenario, ice-shelf-ocean interaction in many places still appears to fully extract the heat content of water getting in touch with the ice base near the grounding line, so that a shift in the grounding line position merely shifts the location of melt rate maxima, but does not increase total melt.

A more substantial and largely unbalanced melt rate increase is found (1) along the ice-shelf front and (2) at locations with a substantial increase in water column thickness. Along the ice-shelf front, increasing melt rates in the A1B scenario lead to a reduction of thickness (only) in the coupled model, reducing its function as a dynamic barrier. Second, reducing ice draft close to the grounding lines leads to an increasing water column thickness below still deep-drafted ice, even if the grounding line position remains unchanged or grounding line migration is very small. In several locations that have already been under the floating ice shelf in the present-day situation, up to $90 \%$ of the water column thickness found at the end of the RAnGO AlB simulation are due to ice-shelf thinning (Fig. 10, panel b). Even though the water mass properties change only very little between $F E$ $S O M A l B$ and $R A n G O A l B$ (Fig. 11), the increased water column thickness in the coupled model allows for a transport of warm water to the deepest parts of the cavity more easily. This is most notable at the estuaries of the Recovery and Support Force glaciers, but also to the north of Bailey Ice Stream. At Support Force Glacier, the increasing melt rates in the A1B scenario lead to a reduced ice-shelf thickness and an increased slope of the ice-shelf base directly off the grounding line (Fig. 11). The latter causes 2195 annual mean along-slope ocean current velocities at the ice-shelf base to increase from about $5 \mathrm{~cm} \mathrm{~s}^{-1}$ in FESOM AIB to a maximum of $15 \mathrm{~cm} \mathrm{~s}^{-1}$ in $R A n G O A 1 B$, reinforcing stronger melt rates in this area and thus forming a positive feedback loop. Some of this increased melting is compensated by a reduced melting in adjacent areas, but the residual remains positive, so that together with the increased melting along the ice front, total ice-shelf basal mass loss in the coupled model increases slightly more than in the fixed-geometry case.

\subsection{Lessons from initial adjustment}

A striking feature in the time series of Fig. 6 is the sudden reduction of FRIS mass and area from 1950 to 1951, i.e. with the first coupling step. What appears as a big discontinuity merely represents $2.7 \%$ of the original ice-shelf mass and $1.0 \%$ of ice-shelf area. Nevertheless, this event deserves a closer look.

While 1950 is the last year in which RIMBAY was run with parameterized melt rates, 1951 is the first year of 

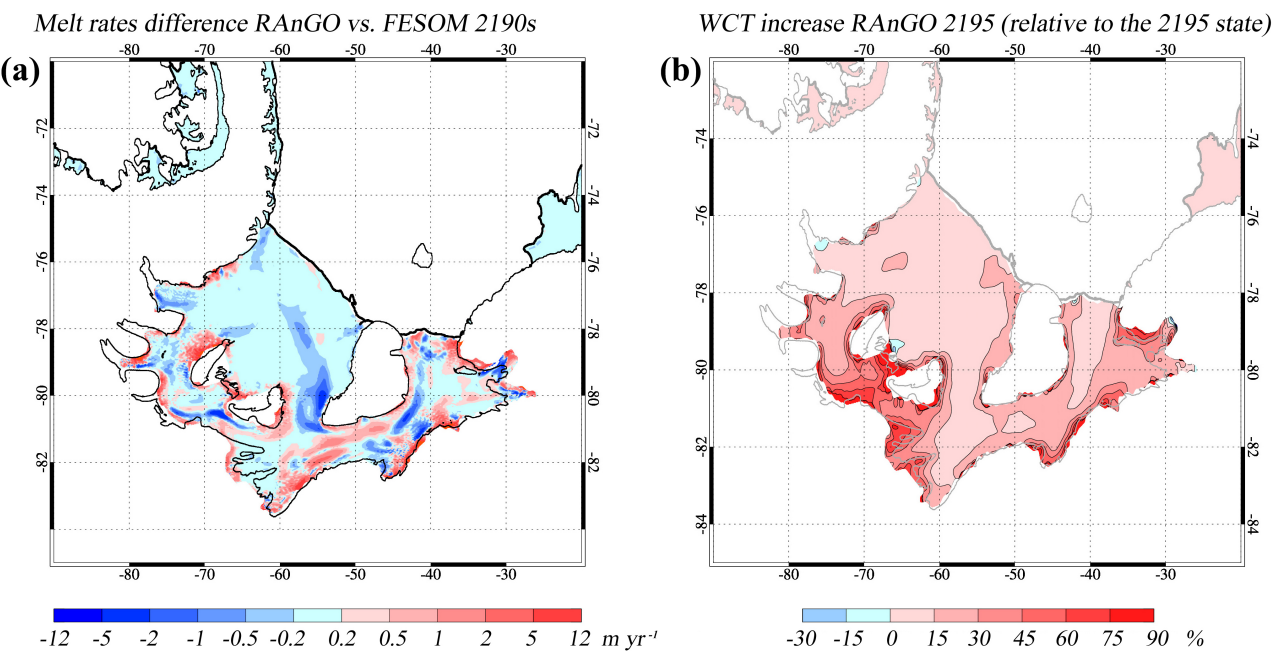

Figure 10. (a) Difference in simulated mean melt rates for the period 2190-2199 in coupled and fixed-geometry simulations (RAnGO minus FESOM). (b) Increase in water column thickness (wct) from FESOM AlB to RAnGO AlB relative to the RAnGO A1B 2195 state. For example, an increase of $90 \%$ at a given location means that $90 \%$ of the water column thickness found in 2195 has been created by ice-shelf thinning.

$R A n G O A 1 B$

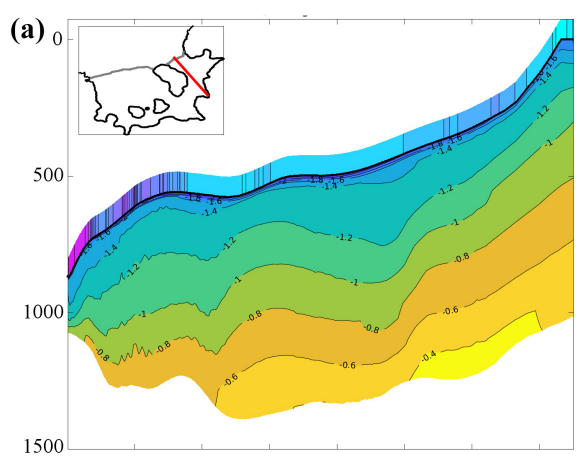

FESOM A1B

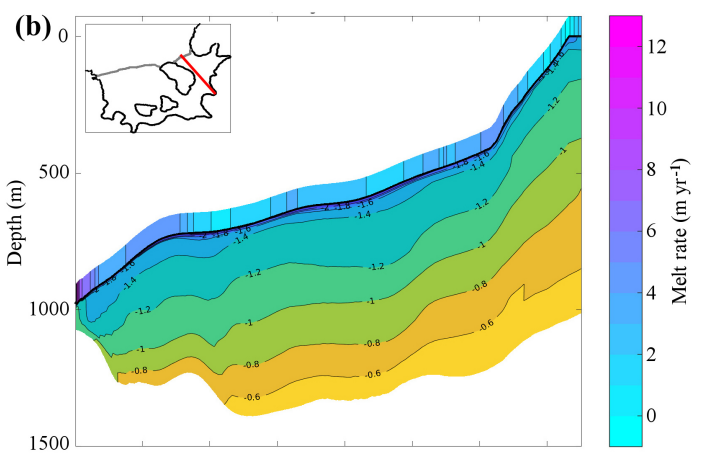

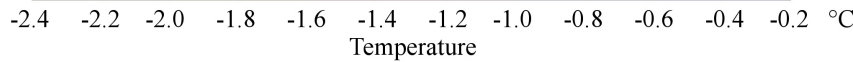

Figure 11. Annual mean potential temperature sections for 2195 below Filchner-Ronne Ice Shelf in $R A n G O A 1 B$ (a) and $F E S O M$ $A 1 B$ (b). Colours on top of the ice-shelf base indicate annual mean basal melt rates. The red lines in the maps indicate the location of the section.

RAnGO, i.e. the first year in which RIMBAY is forced with basal melt rates from FESOM. The top left panel in Fig. 12 thus shows the FRIS thickness distribution at the end of the 1000-year RIMBAY spinup with Beckmann and Goose (2003) melt rates, representing the RIMBAY presentday geometry introduced above. Using this ice thickness distribution, FESOM has been integrated with a fixed cavity geometry for 21 years. Annual-mean melt rates from the last year of this simulation (Fig. 12, bottom left panel) are fed back to RIMBAY as part of the first communication step of the coupled model. Ice thickness distribution after this first $R A n G O$ year (Fig. 12, top right panel) shows that compared to the RIMBAY present-day geometry, ice thickness has reduced mainly in the area south of Berkner Island, i.e. between the Support Force Glacier and the Foundation Ice Stream. The time series of floating ice area (Fig. 6, bottom panel) indicates that some previously floating ice has now become grounded, but grounding line migration is very small. FESOM basal melt rates obtained with this updated ice draft distribution (Fig. 12, bottom right panel) differ only very little from the result of the previous year. We conclude that variations in basal melting affect the ice-shelf thickness distribution quickly and substantially, while the feedback from a perturbed ice thickness distribution on simulated basal melt rates is much weaker. 

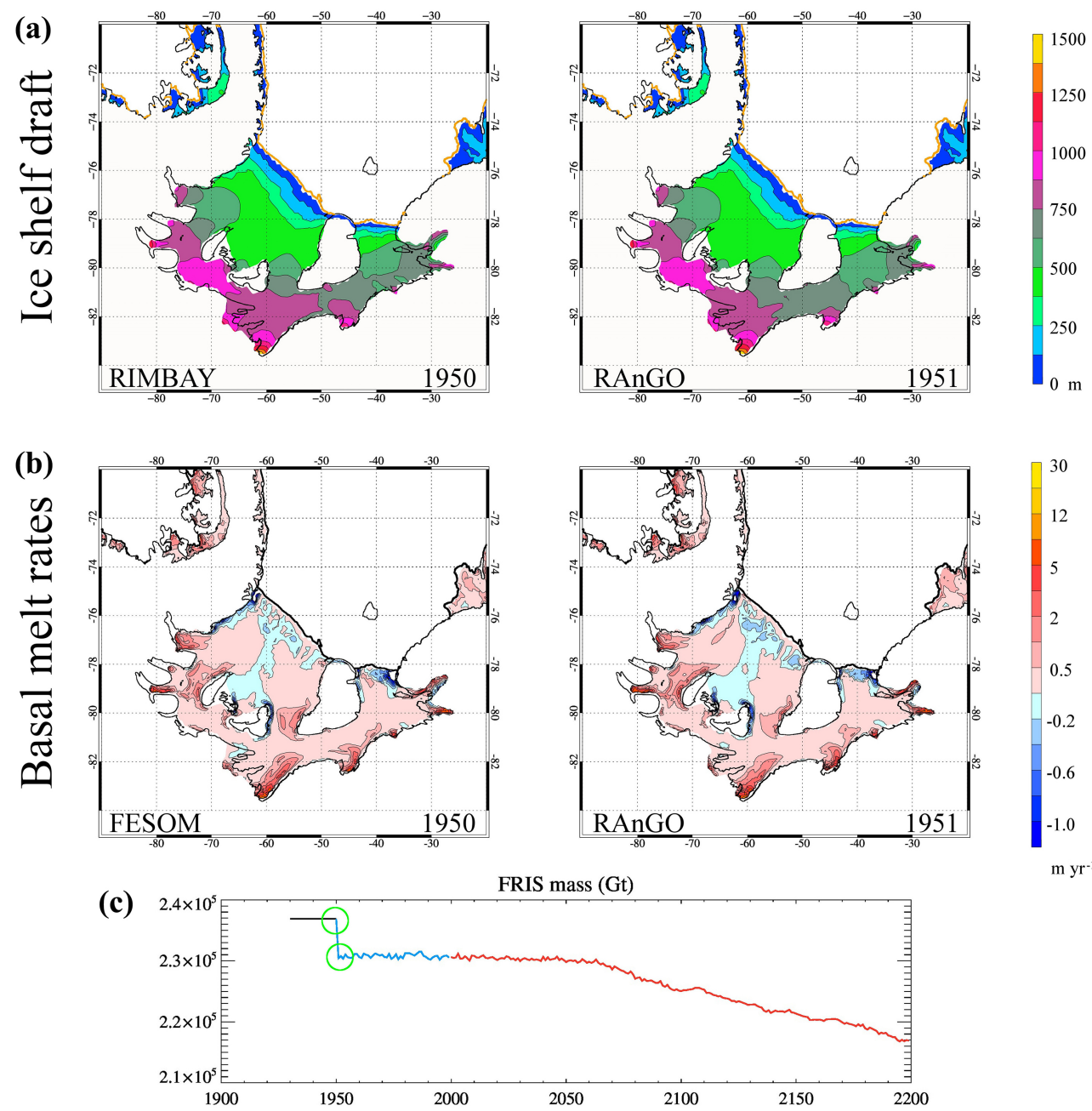

Figure 12. (a) Simulated ice-shelf draft for 1950 and 1951. (b) Simulated basal melt rates averaged over the same years. (c) Time series of FRIS mass with green circles indicating the relevant points in time. The area covered in colours represents the modelled ice-shelf area; black lines indicate coastlines derived from RTopo-2.

\section{Discussion and conclusions}

We have presented the coupled ice sheet-ice shelf-ocean model RAnGO which is focused on the Filchner-Ronne Ice Shelf (FRIS) and the grounded ice in its catchment basin. For present-day climate, the model yields ice-shelf basal melt rates, ice thickness, and grounding line location in good agreement with observations.

As the reference simulation, we used a coupled model run forced with A1B scenario data from the HadCM3 climate model. Similar to the experiments of Hellmer et al. (2012) and Timmermann and Hellmer (2013), a substantial increase in FRIS basal melt rates during the 21st and 22nd centuries occurs as a response to inflowing MWDW in this simulation. This event does not occur in two control simulations (coupled/uncoupled) with a perpetual 20th-century forcing from the same climate model and can thus clearly be attributed to the climate scenario/forcing data used.
Basal mass loss in the coupled A1B simulation increases by a factor of 6 between the simulated 1990s and the projected 2190s; maximum melt rates near the grounding line increase from 4 to $15 \mathrm{~m} \mathrm{year}^{-1}$. Increasing melt rates lead to a thinning of the ice shelf between the present-day situation and the end of the 22nd century, especially in the deepest parts along (but not directly at) the grounding line. Maximum thickness loss in the coupled model is $280 \mathrm{~m}$ and occurs near the grounding line of Support Force Glacier. Grounding line migration does not exceed a distance of about $20 \mathrm{~km}$. A more detailed discussion of dynamics in the various ice streams is provided in Part II of this paper.

Results from the RAnGO coupled model runs indicate that the effect of variations in ice-shelf basal melting on the iceshelf thickness distribution is much stronger than the feedback from a perturbed ice thickness distribution on simulated basal melt rates. This is true for the rapid transition caused by 
switching from Beckmann and Goosse (2003) melt rates to FESOM melt rates as a boundary condition for RIMBAY at the end of the ice model spinup; it is also true for the strongly increased melt rates projected for the end of the 22nd century, which are very similar for the RAnGO AIB and the FESOM $A 1 B$ cavity geometries despite an ice thickness difference of up to $280 \mathrm{~m}$ (i.e. almost $25 \%$ ). We conclude that parameterizing ice-shelf basal melt rates as a function of ice thickness, like in the widely used scheme suggested by Beckmann and Goosse (2003), is not necessarily a good approximation to the governing processes.

Although the basal melt rates are not identical between the coupled and uncoupled simulations, our results indicate that on a timescale of up to 2 centuries, many aspects of iceshelf-ocean interaction at Filchner-Ronne Ice Shelf can be addressed with a fixed ice-shelf geometry even in a changing climate. The long-term trend with basal mass loss increasing by roughly a factor of 6 in the A1B scenario is fully consistent between the coupled and uncoupled simulations. Year-to-year variability of basal mass loss is very similar between the coupled and uncoupled simulations both for A1B scenario forcing and in the 20th-century control runs.

A more quantitative comparison between the $R A n G O A l B$ experiment and the control simulation with A1B forcing but fixed cavity geometry ("FESOM A1B") reveals that the increase in basal melt rate as a response to ice-shelf cavity warming is enhanced by about $12 \%$ in the coupled simulation. The reduced melt potential due to the rising freezing point in areas with decreasing ice thickness in the coupled simulation is clearly outweighed by the increasing water column thickness and the increasing ice base slope, both of which cause a more efficient heat transfer and thus higher melt rates in the deepest part of the cavity. We conclude that using a fixed-geometry ice-shelf-ocean model tends to attenuate rather than exaggerate the response of ice-shelf basal melt rates to ocean climate warming. The long-term evolution of ice-ocean interaction at the shores of Antarctica under progressing climate warming and thus the projection of Antarctica's contribution to future global sea level rise clearly demand an appropriate consideration of coupled processes in regional and global climate models.

Code availability. Codes for RIMBAY and FESOM are available from the authors upon request.

Author contributions. RT set up FESOM, developed and implemented the RAnGO coupling scheme, conducted the experiments, and prepared most of the paper. SG set up the RIMBAY model, provided the RIMBAY interface to the coupling routines, and contributed to the preparation of the paper.
Competing interests. The authors declare that they have no conflict of interest.

Acknowledgements. We would like to thank Klaus Grosfeld, Hartmut Hellmer, Rachael Mueller, Dmitry Sidorenko, and Qiang Wang for helpful discussions; Sina Löschke for supplying the illustration of Weddell Sea continental-shelf processes; Wolfgang Cohrs, Herbert Liegmahl, Natalja Rakowsky, Malte Thoma, and Chresten Wübber for maintaining excellent computing facilities at AWI; and the two anonymous reviewers for their careful reading and helpful suggestions. Frank Schnaase created the scripts for combining sub-ice temperature sections with basal melt rate profiles. We thank the North German Supercomputing Alliance (HLRN) for providing the computer resources required to run FESOM and RAnGO over several hundreds of years. Funding by the Helmholtz Climate Initiative REKLIM (Regional Climate Change), a joint research project of the Helmholtz Association of German Research Centres (HGF), has been indispensable for this study and is gratefully acknowledged.

The article processing charges for this open-access publication were covered by a Research

Centre of the Helmholtz Association.

Edited by: Andreas Sterl

Reviewed by: two anonymous referees

\section{References}

Arthern, R. J., Winebrenner, D. P., and Vaughan, D. G.: Antarctic snow accumulation mapped using polarization of $4.3-\mathrm{cm}$ wavelength microwave emission, J. Geophys. Res.-Atmos., 111, D06107, https://doi.org/10.1029/2004JD005667, 2006.

Beckmann, A. and Goosse, H.: A parameterization of ice shelfocean interaction for climate models, Ocean Model., 5, 157-170, 2003.

Collins, M., Booth, B. B. B., Bhaskaran, B., Harris, G. R., Murphy, J. M., Sexton, D. M. H., and Webb, M. J.: Climate model errors, feedbacks and forcings: a comparison of perturbed physics and multi-model ensembles, Clim. Dynam., 36, 1737-1766, https://doi.org/10.1007/s00382-010-0808-0, 2011.

Comiso, J. C.: Variability and trends in Antarctic surface temperatures from in situ and satellite infrared measurements, J. Climate, 13, 1674-1696, https://doi.org/10.1175/15200442(2000)013<1674:VATIAS>2.0.CO;2, 2000.

Danilov, S., Wang, Q., Timmermann, R., Iakovlev, N., Sidorenko, D., Kimmritz, M., Jung, T., and Schröter, J.: Finite-Element Sea Ice Model (FESIM), version 2, Geosci. Model Dev., 8, 1747 1761, https://doi.org/10.5194/gmd-8-1747-2015, 2015.

Darelius, E., Fer, I., and Nicholls, K. W.: Observed vulnerability of Filchner-Ronne Ice Shelf to wind-driven inflow of warm deep water, Nature Communications, 7, 12300, https://doi.org/10.1038/ncomms12300, 2016.

De Angelis, H. and Skvarca, P.: Glacier surge after ice shelf collapse, Science, 299, 1560-1562, https://doi.org/10.1126/science.1077987, 2003. 
Depoorter, M. A., Bamber, J. L., Griggs, J. A., Lenaerts, J. T. M., Ligtenberg, S. R. M., van den Broeke, M. R., and Moholdt, G.: Calving fluxes and basal melt rates of Antarctic ice shelves, Nature, 502, 89-92, https://doi.org/10.1038/nature12567, 2013.

Dupont, T. K. and Alley, R. B.: Assessment of the importance of ice-shelf buttressing to ice-sheet flow, Geophys. Res. Lett., 32, L04503, https://doi.org/10.1029/2004GL022024, 2005.

Feldmann, J., Albrecht, T., Khroulev, C., Pattyn, F., and Levermann, A.: Resolution-dependent performance of grounding line motion in a shallow model compared with a full-Stokes model according to the MISMIP3d intercomparison, J. Glaciol., 60, 353-360, 2014.

Fretwell, P., Pritchard, H. D., Vaughan, D. G., Bamber, J. L., Barrand, N. E., Bell, R., Bianchi, C., Bingham, R. G., Blankenship, D. D., Casassa, G., Catania, G., Callens, D., Conway, H., Cook, A. J., Corr, H. F. J., Damaske, D., Damm, V., Ferraccioli, F., Forsberg, R., Fujita, S., Gim, Y., Gogineni, P., Griggs, J. A., Hindmarsh, R. C. A., Holmlund, P., Holt, J. W., Jacobel, R. W., Jenkins, A., Jokat, W., Jordan, T., King, E. C., Kohler, J., Krabill, W., Riger-Kusk, M., Langley, K. A., Leitchenkov, G., Leuschen, C., Luyendyk, B. P., Matsuoka, K., Mouginot, J., Nitsche, F. O., Nogi, Y., Nost, O. A., Popov, S. V., Rignot, E., Rippin, D. M., Rivera, A., Roberts, J., Ross, N., Siegert, M. J., Smith, A. M., Steinhage, D., Studinger, M., Sun, B., Tinto, B. K., Welch, B. C., Wilson, D., Young, D. A., Xiangbin, C., and Zirizzotti, A.: Bedmap2: improved ice bed, surface and thickness datasets for Antarctica, The Cryosphere, 7, 375-393, https://doi.org/10.5194/tc-7-375-2013, 2013.

Goeller, S. and Timmermann, R.: Response to Filchner-Ronne Ice Shelf cavity warming in a coupled ocean-ice sheet model - Part 2: The ice perspective, to be submitted to The Cryosphere, 2017.

Hellmer, H. H. and Olbers, D.: A two-dimensional model for the thermohaline circulation under an ice shelf, Antarct. Sci., 1, 325336, 1989.

Hellmer, H. H., Kauker, F., Timmermann, R., Determann, J., and Rae, J.: Twenty-first-century warming of a large Antarctic iceshelf cavity by a redirected coastal current, Nature, 485, 225228, https://doi.org/10.1038/nature11064, 2012.

Holland, D. M. and Jenkins, A.: Modelling thermodynamic iceocean interactions at the base of an ice shelf, J. Phys. Oceanogr., 29, 1787-1800, 1999.

Jacobs, S. S., Hellmer, H. H., Doake, C. S. M., Jenkins, A., and Frolich, R. M.: Melting of ice shelves and the mass balance of Antarctica, J. Glaciol., 38, 375-387, 1992.

Joughin, I. and Padman, L.: Melting and freezing beneath FilchnerRonne Ice Shelf, Antarctica, Geopys. Res. Lett., 30, 1477, https://doi.org/10.1029/2003GL016941, 2003.

Kusahara, K. and Hasumi, H.: Modeling Antarctic ice shelf responses to future climate changes and impacts on the ocean, J. Geophys. Res.-Oceans, 118, 2454-2475, https://doi.org/10.1002/jgrc.20166, 2013.

Lambrecht, A., Sandhäger, H., Vaughan, D. G., and Mayer, C.: New ice thickness maps of Filchner-Ronne Ice Shelf, Antarctica, with specific focus on grounding lines and marine ice, Antarct. Sci., 19, 521-532, https://doi.org/10.1017/S0954102007000661, 2007.

Nicholls, K. W., Makinson, K., and Østerhus, S.: Circulation and water masses beneath the northern Ronne
Ice Shelf, Antarctica, J. Geophys. Res., 109, C12017, https://doi.org/10.1029/2004JC002302, 2004.

Paolo, F. S., Fricker, H. A., and Padman, L.: Volume loss from Antarctic ice shelves is accelerating, Science, 348, 327-332, 2015.

Pattyn, F.: A new three-dimensional higher-order thermomechanical ice sheet model: Basic sensitivity, ice stream development, and ice flow across subglacial lakes, J. Geophys. Res., 108, 115, https://doi.org/10.1029/2002JB002329, 2003.

Pritchard, H. D., Ligtenberg, S. R. M., Fricker, H. A., Vaughan, D. G., van den Broeke, M. R., and Padman, L.: Antarctic ice-sheet loss driven by basal melting of ice shelves, Nature, 484, 502-505, https://doi.org/10.1038/nature10968, 2012.

Rignot, E., Velicogna, I., van den Broeke, M. R., Monaghan, A., and Lenaerts, J. T. M.: Acceleration of the contribution of the Greenland and Antarctic ice sheets to sea level rise, Geophys. Res. Lett., 38, L05503, https://doi.org/10.1029/2011GL046583, 2011.

Rignot, E., Jacobs, S., Mouginot, J., and Scheuchl, B.: Iceshelf melting around Antarctica, Science, 341, 266-270, https://doi.org/10.1126/science.1235798, 2013.

Schaffer, J., Timmermann, R., Arndt, J. E., Kristensen, S. S., Mayer, C., Morlighem, M., and Steinhage, D.: A global, highresolution data set of ice sheet topography, cavity geometry, and ocean bathymetry, Earth Syst. Sci. Data, 8, 543-557, https://doi.org/10.5194/essd-8-543-2016, 2016.

Shapiro, N. M. and Ritzwoller, M. H.: Inferring surface heat flux distributions guided by a global seismic model: particular application to Antarctica, Earth Planet. Sc. Lett., 223, 213-224, https://doi.org/10.1016/j.epsl.2004.04.011, 2004.

Thoma, M., Grosfeld, K., Barbi, D., Determann, J., Goeller, S., Mayer, C., and Pattyn, F.: RIMBAY - a multi-approximation 3D ice-dynamics model for comprehensive applications: model description and examples, Geosci. Model Dev., 7, 1-21, https://doi.org/10.5194/gmd-7-1-2014, 2014.

Timmermann, R. and Hellmer, H. H.: Southern Ocean warming and increased ice shelf basal melting in the 21st and 22nd centuries based on coupled ice-ocean finite-element modelling, Ocean Dynam., 63, 1011-1026, https://doi.org/10.1007/s10236-013-0642$0,2013$.

Timmermann, R., Le Brocq, A., Deen, T., Domack, E., Dutrieux, P., Galton-Fenzi, B., Hellmer, H., Humbert, A., Jansen, D., Jenkins, A., Lambrecht, A., Makinson, K., Niederjasper, F., Nitsche, F., Nøst, O. A., Smedsrud, L. H., and Smith, W. H. F.: A consistent data set of Antarctic ice sheet topography, cavity geometry, and global bathymetry, Earth Syst. Sci. Data, 2, 261-273, https://doi.org/10.5194/essd-2-261-2010, 2010.

Timmermann, R., Wang, Q., and Hellmer, H. H.: Ice shelf basal melting in a global finite-element sea iceice shelf-ocean model, Ann. Glaciol., 53, 303-314, https://doi.org/10.3189/2012AoG60A156, 2012.

Wang, Q., Danilov, S., Sidorenko, D., Timmermann, R., Wekerle, C., Wang, X., Jung, T., and Schröter, J.: The Finite Element Sea Ice-Ocean Model (FESOM) v.1.4: formulation of an ocean general circulation model, Geosci. Model Dev., 7, 663693, https://doi.org/10.5194/gmd-7-663-2014, 2014. 